\title{
Eficácia de Herbicidas em Diferentes Quantidades de Palha de CANA-DE-AÇÚCAR NO CONTROLE DE Euphorbia heterophylla ${ }^{1}$
}

\author{
Efficacy of Herbicides in Different Amounts of Sugar Cane Straw on Euphorbia heterophylla \\ Control
}

\begin{abstract}
MONQUERO, P.A. ${ }^{2}$, AMARAL, L.R. ${ }^{3}$, SILVA, A.C. ${ }^{4}$, SILVA, P.V. ${ }^{5}$ e BINHA, D.P. ${ }^{5}$
RESUMO - Este trabalho foi realizado com o objetivo de estudar o efeito de diferentes quantidades de palha de cana-de-açúcar, colhida sem queima prévia do canavial, sobre a eficácia de alguns herbicidas recomendados para esta cultura. O experimento foi conduzido em campo no Centro de Ciências Agrárias/UFSCar, em Araras, SP. Os tratamentos consistiram dos herbicidas trifloxysulfuron-sodium + ametryn $\left(1.463+37 \mathrm{~g}\right.$ i.a ha' $\left.{ }^{-1}\right)$, imazapic $\left(84 \mathrm{~g}\right.$ i.a ha $\left.{ }^{-1}\right)$, imazapyr $\left(200 \mathrm{~g}\right.$ i.a ha $\left.{ }^{-1}\right),{ }^{1}$ diuron + hexazinone $\left(1.170+330 \mathrm{~g}^{\text {i.a }}\right.$ ha $\left.^{-1}\right) \mathrm{e}^{2}$ diuron + hexazinone $\left(1.330+160 \mathrm{~g}\right.$ i.a ha $\left.{ }^{-1}\right)$ aplicados em pré-emergência de Euphorbia heterophylla e sobre cinco quantidades de palha de cana-de-açúcar $\left(0,5,10,15\right.$ e $\left.20 \mathrm{t} \mathrm{ha}^{-1}\right)$. A eficácia de controle das plantas daninhas foi avaliada aos 7, 14, 21 e 28 dias após a aplicação dos tratamentos (DAT). A palha (15 e $\left.20 \mathrm{t} \mathrm{ha}^{-1}\right)$ reduziu a população de E. heterophylla. À medida que se aumentou a quantidade de palha, houve redução na eficácia dos herbicidas; com $15 \mathrm{t} \mathrm{ha}^{-1}$ de palha, o controle foi considerado satisfatório $(90 \%)$ apenas para os tratamentos ${ }^{1}$ diuron + hexazinone e trifloxysulfuron-sodium + ametryn. Com $20 \mathrm{t} \mathrm{ha}^{-1}$, nenhum herbicida foi eficaz; entretanto, a palha foi eficiente na supressão dessa espécie, verificando-se que o número de plantas emergidas foi menor mesmo na testemunha.
\end{abstract}

Palavras-chave: cobertura morta, amendoim-bravo, controle químico, Saccharum spp.

\begin{abstract}
This work aimed to study the effect of different amounts of sugar cane straw, collected unburned, on the efficacy of some herbicides recommended for this culture. The experiment was carried out in the field, at the Centro de Ciências Agrárias/UFSCar, Araras, SP. The treatments consisted of herbicides trifloxysulfuron-sodium + ametryn $(1,463+37 \mathrm{~g}$ a.i ha-1), imazapic

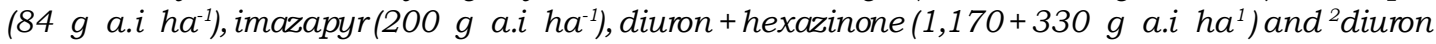
+ hexazinone $\left(1,330+160 \mathrm{~g}\right.$ a.i ha $\left.\mathrm{h}^{-1}\right)$ applied in pre emergence of Euphorbia heterophylla and

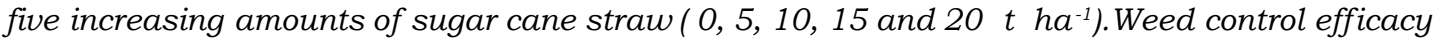
was evaluated on 7, 14, 21 and 28 days after treatments (DAT). Straw (15 and $20 t h a^{1}$ ) reduced the population of $\boldsymbol{E}$. heterophylla. As the amount of straw increased, herbicide effectiveness decreased; with $15 t \mathrm{ha}^{1}$ straw, control was satisfactory (90\%) only for the treatments ${ }^{1}$ diuron + hexazinone and trifloxysulfuron-sodium + ametryn. With $20 \mathrm{t}$ ha $\mathrm{I}^{1}$ straw, no herbicide was effective; however, in this case, straw was efficient in suppressing this species, since the number of emerged plants was smaller, even in the plots without herbicide.
\end{abstract}

Keywords: mulching, wild poinsettia, chemical control, Saccharum spp.

1 Recebido para publicação em 31.1.2007 e na forma revisada em 31.8.2007.

2 Professora Adjunta do Centro de Ciên cias Agrárias/UFSCar, Rodovia Anhanguera, km 174, 13600-970, Araras, SP, <pamonque@cca.ufscar.br>; ${ }^{3}$ Aluno de Graduação do Centro de Ciências Agrárias/UFSCar - Bolsista da Fapesp; ${ }^{4}$ Pesquisadora Científica do Pólo Regional da Alta Sorocabana, Rodovia Raposo Tavares, km 561 Caixa Postal 298, 19015-970 Presidente Pruden te-SP; ${ }^{5}$ Alunos de Graduação do Centro de Ciências Agrárias/UFSCar. 


\section{INTRODUÇÃO}

Os impactos ambientais e sociais levaram à proibição da queimada em canaviais no Estado de São Paulo, segundo esquema de restrições legais progressivas até o ano de 2021, em áreas com possibilidade de mecanização total da colheita, e até 2031, para as demais áreas (Decreto no 47.700, de 11.3.2003, que regulamenta a Lei no 11.241, de 19.9.2002) (Timossi \& Durigan, 2006). Assim, em áreas de colheita mecanizada da cana-crua, permanecerá sobre o solo uma espessa camada de palha, que pode superar $20 \mathrm{t} \mathrm{ha}^{-1}$, fato que influencia diretamente a ocorrência e o manejo de plantas daninhas (Velini \& Negrisoli, 2000).

A cobertura morta ocasiona mudanças químicas, físicas e biológicas no solo, podendo provocar seleção da comunidade infestante, suprimindo a infestação de plantas daninhas normalmente consideradas importantes nos canaviais, como Digitaria horizontalis, Brachiaria plantaginea, B. decumbense Panicum maximum (Velini et al., 2000; Medeiros, 2001; Gravena et al., 2004). No entanto, o mesmo não ocorre com Euphorbia heterophyllae Ipomoea grandifolia, que estão surgindo como plantas-problema no sistema de cana-crua (Martins et al., 1999; Rossi et al., 2006a, b).

A manutenção da palha sobre a superficie do solo pode, simultaneamente, reduzir o potencial de infestação das plantas daninhas, bem como dificultar o desempenho dos herbicidas, uma vez que a água de chuva se torna a principal responsável pelo transporte do herbicida até a superficie do solo (Maciel \& Velini, 2005; Simoni et al., 2006).

Atualmente, o principal método de controle das plantas daninhas é o químico, por meio da aplicação de herbicidas em pré e pós-emergência das espécies. Segundo Freitas et al. (2004), o controle químico de plantas daninhas em áreas de cana-de-açúcar é uma prática bastante difundida em todo o País. Entre as diversas opções de herbicidas registrados para a cultura da cana-de-açúcar encontram-se aqueles inibidores da acetolactato sintase (ALS), como imazapic, imazapyr, trifloxysulfuron-sodium (em mistura com ametryn), halosulfuron e flazasulfuron, e os herbicidas inibidores da fotossintese, como o diuron isoladamente ou em mistura com hexazinone, ametryn, metribuzin e tebuthiuron. A maioria desses herbicidas apresenta ação em pré e pósemergên cia inicial, sendo recomendados no controle de gramineas, folhas largas e perenes de dificil controle. Além disso, podem apresentar periodo de controle efetivo nos solos superior a 100 dias (Procópio et al., 2004).

Diversos autores têm realizado pesquisas sobre a lixiviação e ação dos herbicidas através da palha de cana-de-açúcar deixada sobre a superficie do solo. Segundo Cavenaghi et al. (2006a), com o aumento da quantidade de palha de cana sobre o solo, ocorre diminuição da quantidade do imazapic lixiviado pela chuva, principalmente na quantidade de $20 \mathrm{t} \mathrm{ha}^{-1}$ de palha. O mesmo resultado foi observado com amicarbazone (Cavenaghi et al., 2006b).

$\mathrm{Na}$ presença de até $10 \mathrm{t} \mathrm{ha}^{-1}$ de palha de cana-de-açúcar, o controle das plantas daninhas Sennaobtusifolia, Ipomoea nil, I. hederifolia e I. grandifolia foi satisfatório quando aplicado o herbicida trifloxysulfuron-sodium + ametryn. Quantidades maiores de palha reduziram a ação desse herbicida (Gravena et al., 2004).

Em outro estudo, observou-se que os herbicidas sulfentrazone e imazapic foram eficazes no controle de Cyperus rotundus apenas quando não havia cobertura de solo com a palha da cana remanescente da colheita (Durigan et al., 2004). Já Azania et al. (2004) constataram que uma camada de palha de $15 \mathrm{t} \mathrm{ha}^{-1}$ possui potencial em reter o herbicida imazapic, especialmente sob períodos de pouca precipitação ou irrigação.

Medeiros et al. (2004) desenvolveram experimento para avaliar a eficácia do herbicida imazapic no controle de tiririca em presença de palha de cana-de-açúcar e concluíram que, mesmo que após a aplicação do herbicida ocorra um periodo de seca de até 60 dias, a transposição do herbicida imazapic através da palha de cana, nas doses de 123 e $147 \mathrm{~g} \mathrm{ha}^{-1}$, é altamente significativa, independentemente da quantidade de água (10 ou $20 \mathrm{~mm}$ ) aplicada após a aplicação do herbicida.

Simoni et al. (2006) concluíram que, para o herbicida sulfentrazone, a presença de $20 \mathrm{t} \mathrm{ha}^{-1}$ de palha de cana-de-açúcar diminuiu a eficácia do herbicida; já o herbicida imazapic teve bom desempenho tanto na ausência 
quanto na presença de palha, independentemente da intensidade de chuva.

Objetivou-se com este trabalho avaliar a eficácia de três herbicidas inibidores da acetolactato sintase (ALS) e dois herbicidas inibidores da fotossintese, utilizados na agroindústria canavieira para controle de Euphorbia heterophylla, quando aplicados sobre diferentes quantidades de palha.

\section{MATERIAL E MÉTODOS}

O experimento foi realizado no municipio de Araras-SP, localizado a $22^{\circ} 18^{\prime} 25^{\prime \prime}$ de latitude sul e $47^{\circ} 18^{\prime} 03^{\prime \prime}$ de longitude oeste, entre 25.5.2006 e 30.6.2006. O clima, pela classificação de Köppen, é do tipo Cwa, mesotérmico, com verões quentes e úmidos e invernos secos. $\mathrm{A}$ análise química do solo revelou $\mathrm{pH}$ em $\mathrm{CaCl}_{2}$ de 5,$3 ; 22 \mathrm{~g} \mathrm{dm}^{-3}$ de matéria or gânica; $12 \mathrm{mg} \mathrm{dm}^{-3}$ de $\mathrm{P}$ resina; $\mathrm{V}$ de $63 \%$; e teores de $\mathrm{K}, \mathrm{Ca}, \mathrm{Mg}, \mathrm{H}+\mathrm{Al}$ e $\mathrm{SB}$ de 2,$3 ; 28 ; 11 ; 24$; e $41,3 \mathrm{mmol}_{\mathrm{c}} \mathrm{dm}^{-3}$, respectivamente. Foram monitoradas a temperatura média e a precipitação pluvial referentes ao período de condução do ensaio (Tabela 1).

A espécie $E$. heterophylla foi semeada em parcelas de $3 \mathrm{~m}^{2}$, com a finalidade de obter 100 plantas por unidade experimental. Após a semeadura, foram colocadas quantidades crescentes de palha de cana-de-açúcar, equivalentes a $0,5,10,15$ e $20 \mathrm{t} \mathrm{ha}^{-1}$. O delineamento experimental foi de blocos ao acaso, em esquema fatorial $5 \times 5$, sendo cinco herbicidas e cinco niveis de palha e quatro repetições. Na área escolhida para instalação do experimento não havia infestação natural dessa espécie daninha.
Os tratamentos constaram dos herbicidas trifloxysulfu ron-sodium + ametryn $(1.463+$ $37 \mathrm{~g}$ i.a ha-1), imazapic (84 g i.a ha $\left.{ }^{-1}\right)$, imazapyr $\left(200 \mathrm{~g}\right.$ i.a ha $\left.\mathrm{h}^{-1}\right),{ }^{1}$ diuron + hexazinone $(1.170+$ $330 \mathrm{~g}$ i.a ha-1 $\mathrm{e}^{2}$ diuron + hexazinone $(1.330+$ $160 \mathrm{~g}$ i.a ha ${ }^{-1}$ ), aplicados em pré-emergência no dia 28.5.2006, aos dois dias após a semeadura. Os herbicidas foram aplicados com pulverizador costal pressurizado por $\mathrm{CO}_{2}$, à pressão constante de 2,5 kgf $\mathrm{cm}^{2}$, barra de aplicação provida de bicos com pontas de pulverização do tipo leque 110.03 e consumo de calda de $200 \mathrm{~L} \mathrm{ha}^{-1}$. A umidade relativa do ar durante a aplicação foi de $60 \%$, com temperatura de $28{ }^{\circ} \mathrm{C}$ e velocidade do vento de $4,0 \mathrm{~km} \mathrm{~h}^{-1}$. Cada herbicida foi aplicado sobre as diferentes quantidades de palha de cana-de-açúcar. Após 24 horas, foi simulada chuva de $14 \mathrm{~mm}$. Essa simulação foi feita a cada dois dias após a aplicação dos herbicidas, utilizando-se um sistema de irrigação por aspersão.

O controle das plantas daninhas foi avaliado por meio de escala visual aos $7,14,21 \mathrm{e}$ 28 dias depois da aplicação dos tratamentos (DAT), por meio de uma escala percentual de notas, em que 0 correspondeu a nenhuma injúria na planta e 100, à morte das plantas. Na última avaliação, a palha foi retirada cuidadosamente das parcelas e contado o número de plantas emergidas de E. heterophylla.

Os resultados foram submetidos à análise de variância. Para interação significativa entre herbicidas e niveis de palha, na última avaliação, foi feito o desdobramento e aplicouse o teste de Tukey a 5\% de probabilidade. Para efeito de época de avaliação e de dose de palha, foi empregada a análise de regressão.

Tabela 1 - Dados climatológicos da região de Araras, durante a condução do experimento

\begin{tabular}{|c|c|c|c|c|}
\hline \multirow{2}{*}{$\begin{array}{c}\text { Semana após aplicação dos } \\
\text { tratamentos }\end{array}$} & \multicolumn{3}{|c|}{ Temperatura $\left({ }^{\circ} \mathrm{C}\right)$} & \multirow[b]{2}{*}{$\begin{array}{c}\text { Chuva } \\
(\mathrm{mm})\end{array}$} \\
\hline & $\begin{array}{l}\text { Temperatura } \\
\text { máxima }\end{array}$ & $\begin{array}{l}\text { Temperatura } \\
\text { mínima }\end{array}$ & $\begin{array}{l}\text { Temperatura } \\
\text { média }\end{array}$ & \\
\hline $1^{\mathrm{a}}$ & 26,0 & 12,3 & 19,2 & - \\
\hline $2^{-\mathrm{a}}$ & 22,5 & 9,8 & 16,2 & 8,0 \\
\hline $3^{\mathrm{a}}$ & 26,8 & 10,8 & 18,8 & - \\
\hline $4^{\mathrm{a}}$ & 26,9 & 11,0 & 19,0 & 1,2 \\
\hline
\end{tabular}




\section{RESULTADOS E DISCUSSÃO}

Houve interação significativa entre os diferentes niveis de palha e os herbicidas no controle de E. heterophylla. O desdobramento da interação aos 28 DAT é apresentado na Tabela 2.

Com $20 \mathrm{t} \mathrm{ha}^{-1}$, a porcentagem de controle de todos os herbicidas foi muito baixa, em torno de 30 a $60 \%$; entretanto, observou-se que, nesse caso, a própria palha foi eficiente na supressão desta espécie, já que o número de plantas emergidas foi menor à medida que se aumentou a quantidade de palha, mesmo na testemunha (Figura 5).

Observou-se diferença significativa na eficácia dos herbicidas nos diferentes níveis de palha. Os herbicidas imazapyr, trifloxysulfuron-sodium + ametryn e ${ }^{1}$ diuron + hexazinone foram interceptados com quantidade de palha de $20 \mathrm{t} \mathrm{ha}^{-1}$. Todavia, os herbicidas imazapic e ${ }^{2}$ diuron + hexazinone foram mais retidos pela palha, mostrando redução da eficácia a partir de $15 \mathrm{t} \mathrm{ha}^{-1}$ de palha.

Quanto aos herbicidas, dentro de cada nível de palha, verificou-se que até $10 \mathrm{t} \mathrm{ha}^{-1}$ de palha não houve diferença entre os herbicidas. No nivel de $15 \mathrm{t} \mathrm{ha}^{-1}$ de palha, o pior desempenho foi obtido pela mistura ${ }^{2}$ diuron + hexazinone, seguido pelo imazapic. Com $20 \mathrm{t} \mathrm{ha}^{-1}$, o melhor desempenho foi obtido pelo trifloxysulfuron-sodium + ametryn, com 60\% de controle, e os piores, por imazapic e imazapyr, com 30 e $27,5 \%$ de controle, respectivamente.

Na Figura 1, observa-se o controle de $E$. heterophylla quando os herbicidas foram aplicados em parcelas sem a palha de cana-

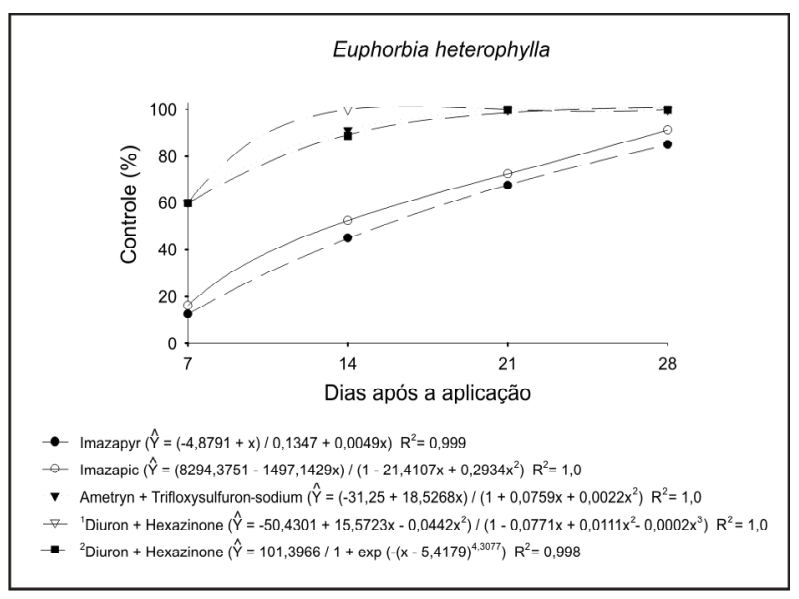

Figura 1 - Eficácia dos herbicidas imazapyr, imazapic, ametryn + trifloxysulfuron-sodium, ${ }^{1}$ diuron + hexazinone $\mathrm{e}^{2}$ diuron + hexazinone sobre E. heterophylla, avaliada aos 7, 14, 21 e 28 DAT, nas parcelas sem palha de cana-de-açúcar.

de-açúcar. As misturas que apresentavam os ingredientes ativos diuron + hexazinone e trifloxysulfuron-sodium + ametryn tive ram efeito mais rápido sobre as plantas daninhas, aproximando-se de $100 \%$ de controle aos 21 DAT, enquanto os herbicidas imazapic e imazapyr apresentaram controle dessa espécie, nessa mesma avaliação, em torno de $60 \%$. Segundo Rodrigues \& Almeida (2005), as plantas afetadas pelos herbicidas inibidores da acetolactato sintase são levadas lentamente à morte; contudo, já poucas horas após o tratamento, o crescimento é estagnado, com inibição da divisão celular.

Nas Figuras 2 e 3, ou seja, com 5 e $10 \mathrm{t} \mathrm{ha}^{-1}$ de palha, não foi observada grande diferença de resposta de controle dos herbicidas em relação ao tratamento sem palha. Aos 28 DAT

Tabela 2 - Controle de E. heterophylla em função de diferentes herbicidas e níveis de palha, avaliado aos 28 dias após a aplicação

\begin{tabular}{|c|c|c|c|c|c|}
\hline \multirow{2}{*}{ Herbicida } & \multicolumn{5}{|c|}{ Palha de cana-de-açúcar (t ha $\left.{ }^{-1}\right)$} \\
\cline { 2 - 6 } & 0 & 5 & 10 & 15 & 20 \\
\hline imazapyr & $85,00 \mathrm{aA}$ & $87,50 \mathrm{aA}$ & $87,50 \mathrm{aA}$ & $80,0 \mathrm{aA}$ & $30,0 \mathrm{bcB}$ \\
\hline imazapic & $91,25 \mathrm{aA}$ & $91,25 \mathrm{aA}$ & $83,75 \mathrm{aA}$ & $55,0 \mathrm{bB}$ & $27,5 \mathrm{cC}$ \\
\hline trifloxysulfuron-sodium + ametryn & $100,00 \mathrm{aA}$ & $100,00 \mathrm{aA}$ & $92,50 \mathrm{aA}$ & $90,0 \mathrm{aA}$ & $60,0 \mathrm{aB}$ \\
\hline 'diuron + hexazinone & $100,00 \mathrm{aA}$ & $100,00 \mathrm{aA}$ & $95,00 \mathrm{aA}$ & $90,0 \mathrm{aA}$ & $45,0 \mathrm{abB}$ \\
\hline 2diuron + hexazinone & $100,00 \mathrm{aA}$ & $97,50 \mathrm{aA}$ & $91,25 \mathrm{aA}$ & $30,0 \mathrm{cB}$ & $37,5 \mathrm{bcB}$ \\
\hline
\end{tabular}




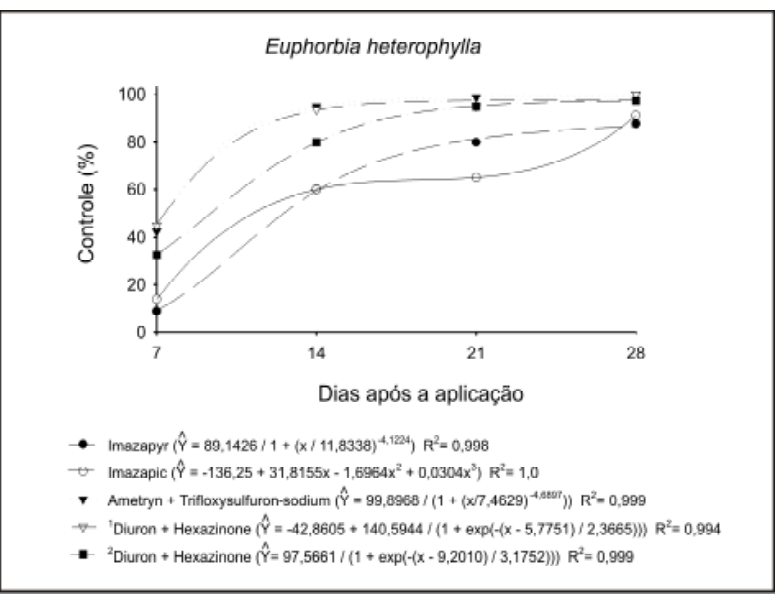

Figura 2 - Eficácia dos herbicidas imazapyr, imazapic, ametryn + trifloxysulfuron-sodium, 'diuron + hexazinone $\mathrm{e}^{2}$ diuron + hexazinone sobre E. heterophylla, avaliada aos 7, 14, 21 e 28 DAT, nas parcelas com $5 \mathrm{t} \mathrm{ha}^{-1}$ de palha de cana-deaçúcar.

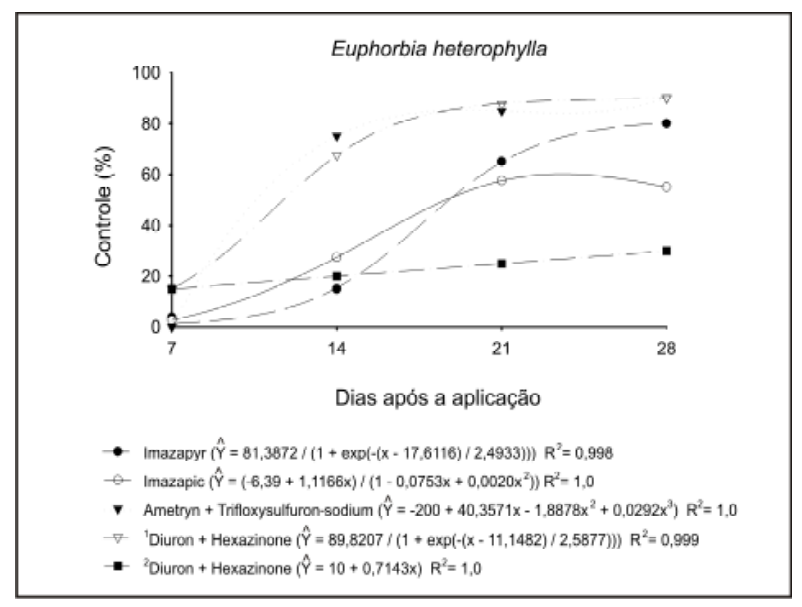

Figura 3 - Eficácia dos herbicidas imazapyr, imazapic, ametryn + trifloxysulfuron-sodium, ${ }^{1}$ diuron + hexazinone $\mathrm{e}^{2}$ diuron + hexazinone sobre E. heterophylla, avaliada aos 7, 14, 21 e 28 DAT, nas parcelas com $10 \mathrm{t} \mathrm{ha}^{-1}$ de palha de cana-deaçúcar.

todos apresentaram eficiente controle de $E$. heterophylla. Com $10 \mathrm{t} \mathrm{ha}^{-1}$ de palha, os herbicidas mais eficazes foram, em ordem crescente: imazapyr $<$ imazapic $<{ }^{2}$ diuron + hexazinone $<$ trifloxysulfuron + ametryn $<{ }^{1}$ diuron + hexazinone.

Com $15 \mathrm{t} \mathrm{ha}^{-1}$ de palha, observou-se significativa redução na eficácia de controle de alguns herbicidas, principalmente do ${ }^{2}$ diuron + hexazinone e imazapic; o primeiro proporcionou controle de apenas 30\%, possivelmente por ser o herbicida que apresenta maior

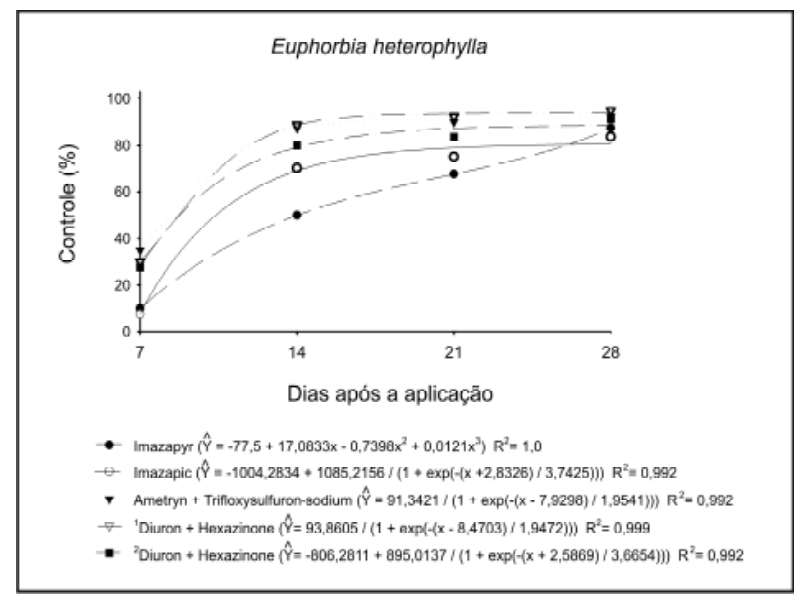

Figura 4 - Eficácia dos herbicidas imazapyr, imazapic, ametryn + trifloxysulfuron-sodium, ${ }^{1}$ diuron + hexazinone $\mathrm{e}^{2}$ diuron + hexazinone sobre $E$. heterophylla, avaliada aos 7, 14, 21 e 28 DAT, nas parcelas com $15 \mathrm{t} \mathrm{ha}^{-1}$ de palha de cana-deaçúcar.

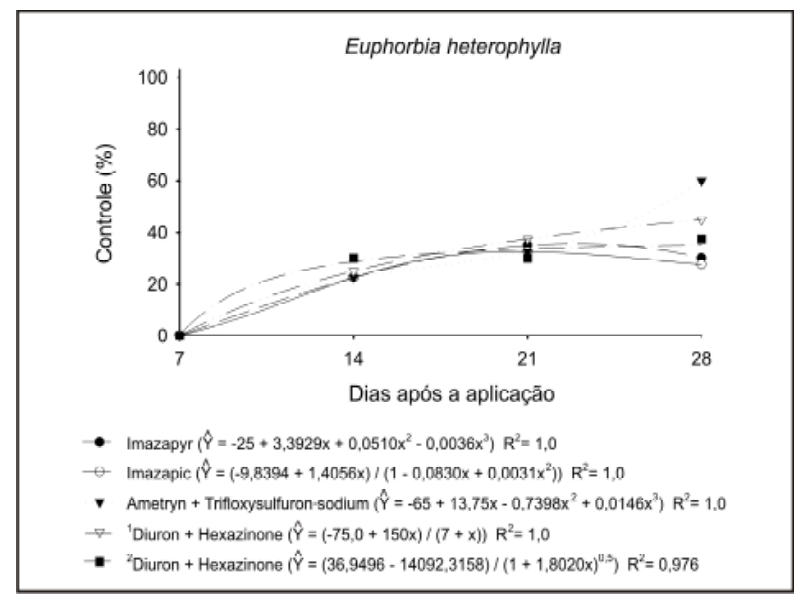

Figura 5 - Eficácia dos herbicidas imazapyr, imazapic, ametryn + trifloxysulfuron-sodium, ${ }^{1}$ diuron + hexazinone e 2 diuron + hexazinone sobre E. heterophylla, avaliada aos 7, 14, 21 e 28 DAT, nas parcelas com $20 \mathrm{t} \mathrm{ha}^{-1}$ de palha de cana-deaçúcar.

predisposição à retenção pela palha, não a atravessando em quantidade suficiente para o controle da espécie. A capacidade de um herbicida residual em atingir o solo, quando coberto por palha, não depende apenas da sua solubilidade em água, fotodecomposição e volatilização. A quantidade, a composição química e a origem da cobertura morta, assim como a quantidade e o período da primeira chuva ou irrigação ocorridas após a aplicação, além das condições climáticas prevalecentes durante e após a aplicação, também podem ser fundamentais (Rodrigues, 1993). 
O controle foi considerado satisfatório apenas nos tratamentos ${ }^{1}$ diuron + hexazinone e trifloxysulfuron-sodium + ametryn (Figura 4). Considerando que essa formulação de diuron + hexazinone apresenta concentração maior de hexazinone, sugere-se que este ingrediente ativo foi mais eficaz em atravessar a palha. Um herbicida de baixa solubilidade como o diuron $\left(42 \mathrm{ppm}\right.$ a $\left.25^{\circ} \mathrm{C}\right)$ necessita de maior teor de umidade no solo para se movimentar e atuar, quando comparado ao hexazinone, de alta solubilidade (29.800 ppm a $25^{\circ} \mathrm{C}$ ) (Bouchard et al., 1985). Os resultados de eficácia obtidos com trifloxysulfuron-sodium + ametryn corroboram os de Gravena et al. (2004), os quais observaram que na presença de $15 \mathrm{t} \mathrm{ha}^{-1}$ de palha de cana-de-açúcar ocorreu controle satisfatório das plantas I. nil, I. grandifolia, I. hederifolia, Sida obtusifolia e Panicum maximum.

Com $20 \mathrm{t} \mathrm{ha}^{-1}$, a porcentagem de controle de todos os herbicidas foi muito baixa, em torno de 30 a $60 \%$; entretanto, observou-se que, nesse caso, a própria palha foi eficiente na supressão desta espécie, já que o número de plantas emergidas foi menor à medida que se aumentou a quantidade de palha, mesmo na testemunha.

A cobertura do solo com 15 e 20 t ha $^{-1}$ de palha, tanto nas parcelas com e sem aplicação de herbicidas, proporcionou redução na emergência de $E$. heteropylla (Figura 6). Nessas quantidades de palha não houve diferenças significativas entre os tratamentos sem herbicida, imazapic, imazapyr e trifloxysulfuronsodium + ametryn, possivelmente pela alta interceptação do herbicida pela palha, que, segundo Velini \& Negrisoli (2000), pode ser aproximadamente $99,5 \%$ da calda aplicada.

Velini \& Negrisoli (2000) observaram que a palha de cana-de-açúcar reduziu drasticamente a variação da temperatura do solo a $1 \mathrm{e}$ $5 \mathrm{~cm}$ de profundidade, o que contribui de modo decisivo para a redução da germinação de plantas daninhas de áreas de cana-crua, pois a amplitude térmica é um dos componentes mais importantes na germinação das sementes de muitas espécies.

Os herbicidas não mostraram controle satisfatório de $E$. heterophylla quando foi utilizada quantidade de palha superior a $15 \mathrm{t} \mathrm{ha}^{-1}$,

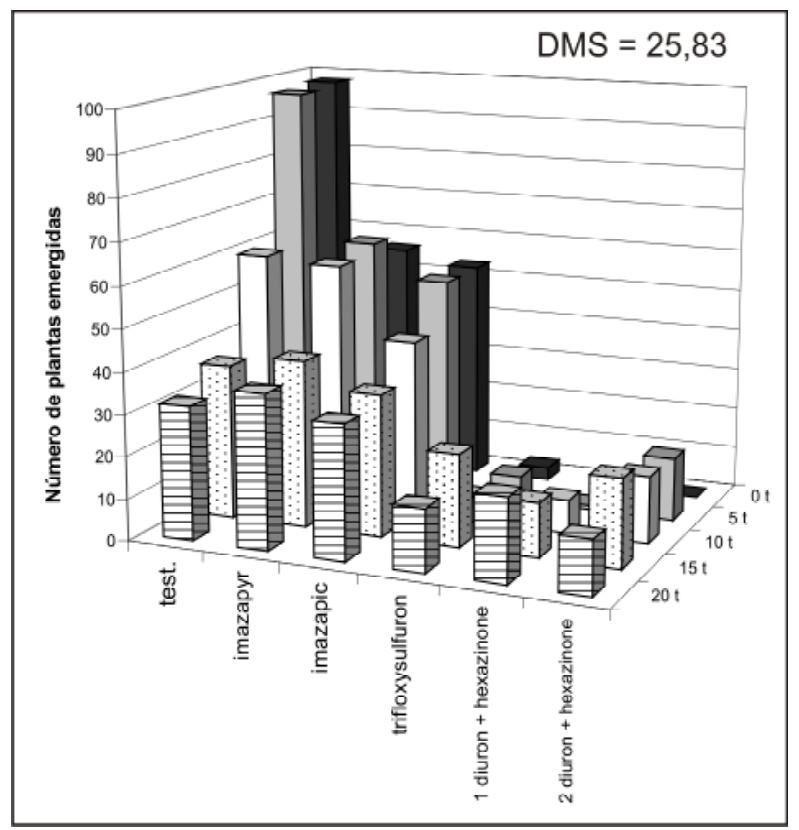

Figura 6 - Plantas daninhas emergidas em diferentes quantidades de palha de cana-de-açúcar e herbicidas (DMS = diferença mínima significativa: $\mathrm{P}<0,05)$.

embora, nesta quantidade, a própria camada de palha possa ser utilizada como fator de supressão desta espécie daninha. Já com até $10 \mathrm{t} \mathrm{ha}^{-1}$ de palha, não foi observada diferença significativa na eficácia dos herbicidas.

\section{AGRADECIMENTOS}

À Fundação de Amparo à Pesquisa do Estado de São Paulo (Fapesp), que proporcionou condições para que esta pesquisa fosse realizada, e aos funcionários Rubens Olivio e Ernesto Favetta.

\section{LITERATURA CITADA}

AZANIA, C. A. M. et al. Seletividade do imazapic para dois cultivares de amendoim (Arachis hypogaea) cultivados na ausência e na presença de palha de cana-de-açúcar. Planta Daninha, v. 22, p. 145-150, 2004.

BOUCHARD, D. C.; LAVY, T. L.; LAWSON, E. R. Mobility and persistence of hexazinone in a forest watershed. J. Environ. Qual., v. 14, p. 229-233, 1985.

CAVENAGHI, A. L. et al. Dinâmica do herbicida imazapic aplicado sobre a palha de cana-de-açúcar. In: CONGRESSO BRASILEIRO DA CIÊNCIA DAS PLANTAS

DANINHAS, 25., 2006, Brasília. Resumos... Brasília: SBCPD; UNB; Embrapa Cerrados, 2006a. p. 360. 
CAVENAGHI, A. L. et al. Performance do herbicida amicarbazone aplicado sobre a palha de cana-de-açúcar. In: CONGRESSO BRASILEIRO DA CIÊNCIA DAS PLANTAS DANINHAS, 25., Brasília, 2006b. Resumos... Brasília: SBCPD; UNB; Embrapa Cerrados, 2006. p. 330.

DURIGAN, J. C.; TIMOSSI, P. C.; LEITE, G. J. Controle químico da tiririca (Cyperus rotundus), com e sem cobertura do solo pela palha de cana-de-açúcar. Planta Daninha, v. 22 , p. $127-135,2004$.

FREITAS, S. P. et al. Controle químico de Rottboelia exaltata em cana-de-açúcar. Planta Daninha, v. 22, p. 461-466, 2004.

GRAVENA, R. et al. Controle de plantas daninhas através da palha de cana-de-açúcar associada à mistura dos herbicidas trifloxysulfuron sodium + ametryn. Planta Daninha, v. 22, p. $419-427,2004$.

MACIEL, C. D. G.; VELINI, E. D. Simulação do caminhamento da água da chuva e herbicidas em palhadas utilizadas em sistemas de plantio direto. Planta Daninha, v. 23, p. 471- 481, 2005.

MARTINS, D. et al. Emergência em campo de dicotiledôneas infestantes em solo coberto com palha de cana-de-açúcar.

Planta Daninha, v. 17, p. 151-161, 1999.

MEDEIROS, D. Efeitos da palha de cana-de-açúcar (Saccharum spp.) sobre o manejo de plantas daninhas e dinâmica do banco de sementes. 2001. 126 f. Dissertação (Mestrado em Fitotecnia) - Escola Superior de Agricultura "Luiz de Queiroz", Piracicaba, 2001.

MEDEIROS, D. et al. Eficácia do herbicida imazapic no controle de tiririca (Cyperus rotundus) em presença de palha de cana-de-açúcar. In: CONGRESSO BRASILEIRO DA CIÊNCIA DAS PLANTAS DANINHAS, 24., 2004, São Pedro. Anais... São Pedro: Sociedade Brasileira da Ciência das Plantas Daninhas, 2004. CD-ROM.
PROCÓPIO, S. O.; SILVA, A. A.; VARGAS, L. Manejo e controle de plantas daninhas em cana-de-açúcar. In.: VARGAS, L.; ROMAN, E. S. (Eds.). Manual de manejo e controle de plantas daninhas. Bento Gonçalves: Embrapa Uva e Vinho, 2004. p. 397-452.

RODRIGUES, B. N.; ALMEIDA, F. S. Guia de herbicidas. 5. ed. Londrina: Edição dos Autores, 2005. $592 \mathrm{p}$.

RODRIGUES, B. N. Influência da cobertura morta no comportamento dos herbicidas imazaquin e clomazone. Planta Daninha, v. 11, p.21-28, 1993.

ROSSI, C. V. S. et al. Efeito da presença de palha de cana crua a germinação de plantas daninhas em época seca. In: CONGRESSO BRASILEIRO DA CIÊNCIA DAS PLANTAS DANINHAS, 25., 2006, Brasília. Resumos... Brasília: SBCPD; UNB; Embrapa Cerrados, 2006a. p. 326.

ROSSI, C. V. S. et al. Efeito da presença de palha de cana crua sobre a germinação de plantas daninhas em época úmida. In: CONGRESSO BRASILEIRO DA CIÊNCIA DAS PLANTAS DANINHAS, 25., 2006, Brasília. Resumos... Brasília: SBCPD; UNB; Embrapa Cerrados, 2006b. p. 346.

SIMONI, F. et al. Eficácia de imazapic e sulfentrazone sobre Cyperus rotundus em diferentes condições de chuva e palha de cana-de-açúcar. Planta Daninha, v. 24, p.769-77 8, 2006.

TIMOSSI, P. C.; DURIGAN, J. C. Manejo de convolvuláceas em dois cultivares de soja semeada diretamente sob palha residual de cana crua. Planta Daninha, v. 24, p. 91-98, 2006.

VELINI, E. D. et al. Efeito da palha da cana-de-açúcar sobre a germinação das principais espécies de plantas daninhas gramíneas desta cultura. In: CONGRESSO BRASILEIRO DA CIÊNCIA DAS PLANTAS DANINHAS, 22., 2000, Foz do Iguaçu. Resumos... Londrina: SBCPD, 2000. p. 15.

VELINI, E. D.; NEGRISOLI, E. Controle de plantas daninhas em cana crua. In: CONGRESSO BRASILEIRO DA CIÊNCIA DAS PLANTAS DANINHAS, 22., 2000, Foz do Iguaçu. Palestras... Foz do Iguaçu: 2000. p. 148-164. 